Supplement of The Cryosphere, 15, 3719-3730, 2021

https://doi.org/10.5194/tc-15-3719-2021-supplement

(C) Author(s) 2021. CC BY 4.0 License.

(c) (i)

Supplement of

\title{
A portable lightweight in situ analysis (LISA) box for ice and snow analysis
}

\section{Helle Astrid Kjær et al.}

Correspondence to: Helle Astrid Kjær (hellek@fys.ku.dk)

The copyright of individual parts of the supplement might differ from the article licence. 
In this supplementary material please find Figures and Tables of the melt head design used in the LISA box (Figures S1 and S2, Table S1). The results from the field season 2017 (Figures S3, Table S2, section S1) and accumulation results from 2019 (Figure S4).

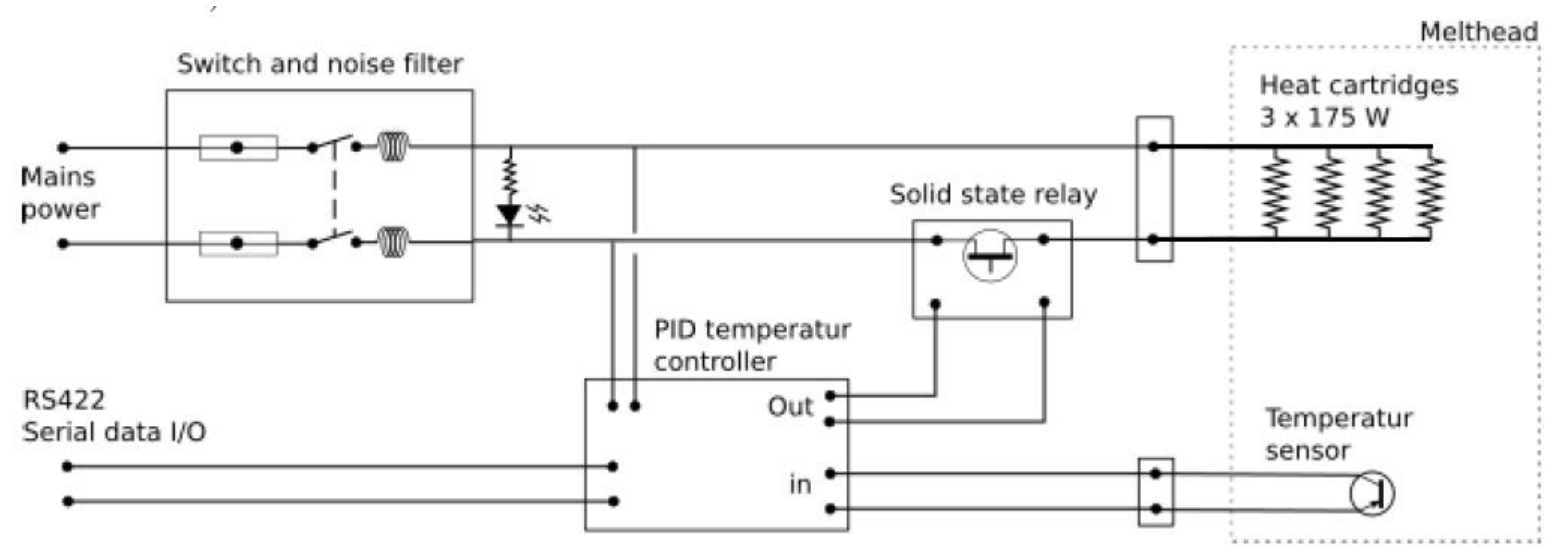

Figure S1. The electrical circuit for the PID controlling the melt head temperature.

Table S1: 4" melt head specifications

\begin{tabular}{lr}
\hline Melt head specifications & \\
\hline Outer diameter & $14 \mathrm{~cm}$ \\
Inner diameter & $11 \mathrm{~cm}$ \\
Height & $6 / 7 \mathrm{~cm}$ \\
Weight & $1.65 \mathrm{~kg}$ \\
Material & Aluminum \\
Inner sample drainage line & 5 \\
Outer waste lines & $1 / 4$ inch \\
Diameter of outlets & $3.76 \mathrm{~cm}^{3}$ \\
Inner cone volume & $7.5 \mathrm{~cm}^{2}$ \\
Surface area inner cone & $91.5 \mathrm{~cm}^{2}$ \\
Surface area outer waste & 4 \\
Heating cartridges & \\
\hline
\end{tabular}



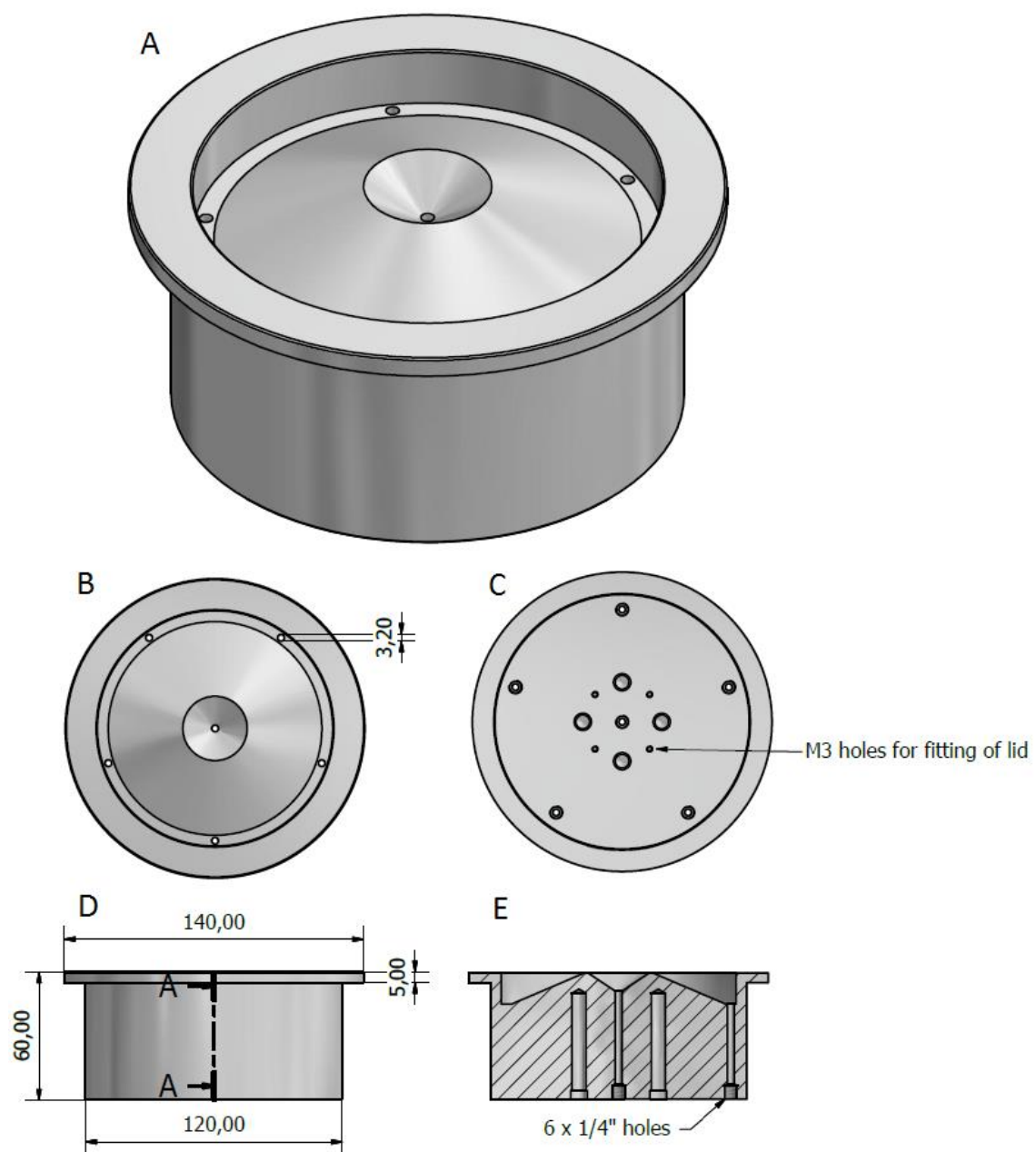

$\mathrm{E}$

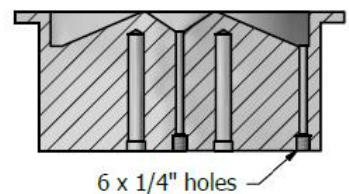

Figure S2: Conical firn melt head used in the LISA box. A) View of entire melt head, B) View from the top. Five drainage holes for outer possibly contaminated sample at the edge and in the center is a drainage hole for the sample going to analysis. C) View from the bottom- in addition to water drainage channels $\mathbf{4}$ holes are made for the heat cartridges, which control the melt head temperature. D) Melt head view from the side with dimensions in $\mathbf{m m}$. E) Melt head cross section view showing the inner structure.

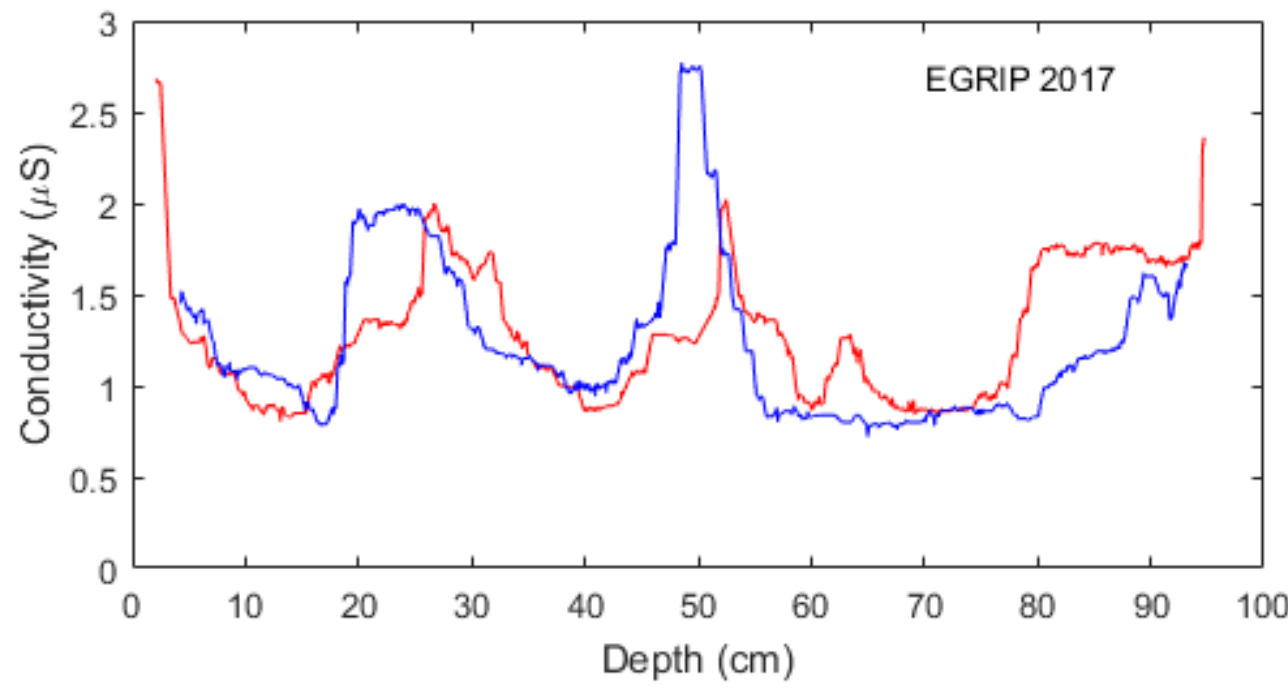

Figure S3: Conductivity as determined using the LISA box in 2017 for two adjacent snow cores. 


\section{S1: 2017 accumulation reconstructions}

For the EastGRIP site (results from 2017) we can also reconstruct the accumulation for the period spring 2014 to spring 2017 (Table S2) based on the assumption that conductivity peaks represent regular springtime peaks of snow acidity ${ }^{34,35}$. By assuming further a mean density in the top 1 meter of $350 \mathrm{~kg} \mathrm{~m}^{-323}$ the annual water equivalent accumulation at EastGRIP was determined to be $10 \pm 3 \mathrm{~cm}$ w.eq annually as shown in Table S2. Since the mean surface density is assumed, and because surface densities as a mean over the top 1 metre in Greenland as observed from the 2019 results vary by between 326 and $378 \mathrm{~kg} \mathrm{~m}^{-3}$, we have in our results from 2017 an additional uncertainty of up to $1 \mathrm{~cm}$ w.eq.

Table S2: Depth of the spring acid layer at EGRIP in 2017 as based on the conductivity peaks and an estimate of EGRIP annual accumulation from spring to spring using an assumed density of $350 \mathrm{~kg} / \mathrm{m} 3$ in the surface 1 metre of snow.

\begin{tabular}{r|rr|rr}
\hline & \multicolumn{2}{|c|}{$\begin{array}{c}\text { Depth of acid layer } \\
(\mathrm{cm})\end{array}$} & \multicolumn{2}{c}{$\begin{array}{c}\text { Accumulation } \\
(\mathrm{cm} \text { w.eq })\end{array}$} \\
\hline & \multicolumn{2}{|c|}{ Core 1 } & \multicolumn{1}{c}{ Core 2 } & \multicolumn{2}{c}{ Core 1 } & Core 2 \\
\hline 2017 & 0 & 0 & & 9.44 \\
2016 & 23.37 & 26.9 & 8.20 & 8.76 \\
2015 & 49.59 & 51.84 & 9.20 & 10.66 \\
2014 & 89.32 & 82.21 & 13.94 & $\mathbf{9 . 6 2 \pm 0 . 7 9}$ \\
\hline Mean & $\mathbf{2 9 . 7 7 \pm 7 . 1 4}$ & $\mathbf{2 7 . 4 0 \pm 2 . 2 5}$ & $\mathbf{1 0 . 4 5} \pm \mathbf{2 . 5 0}$ & \\
\hline
\end{tabular}



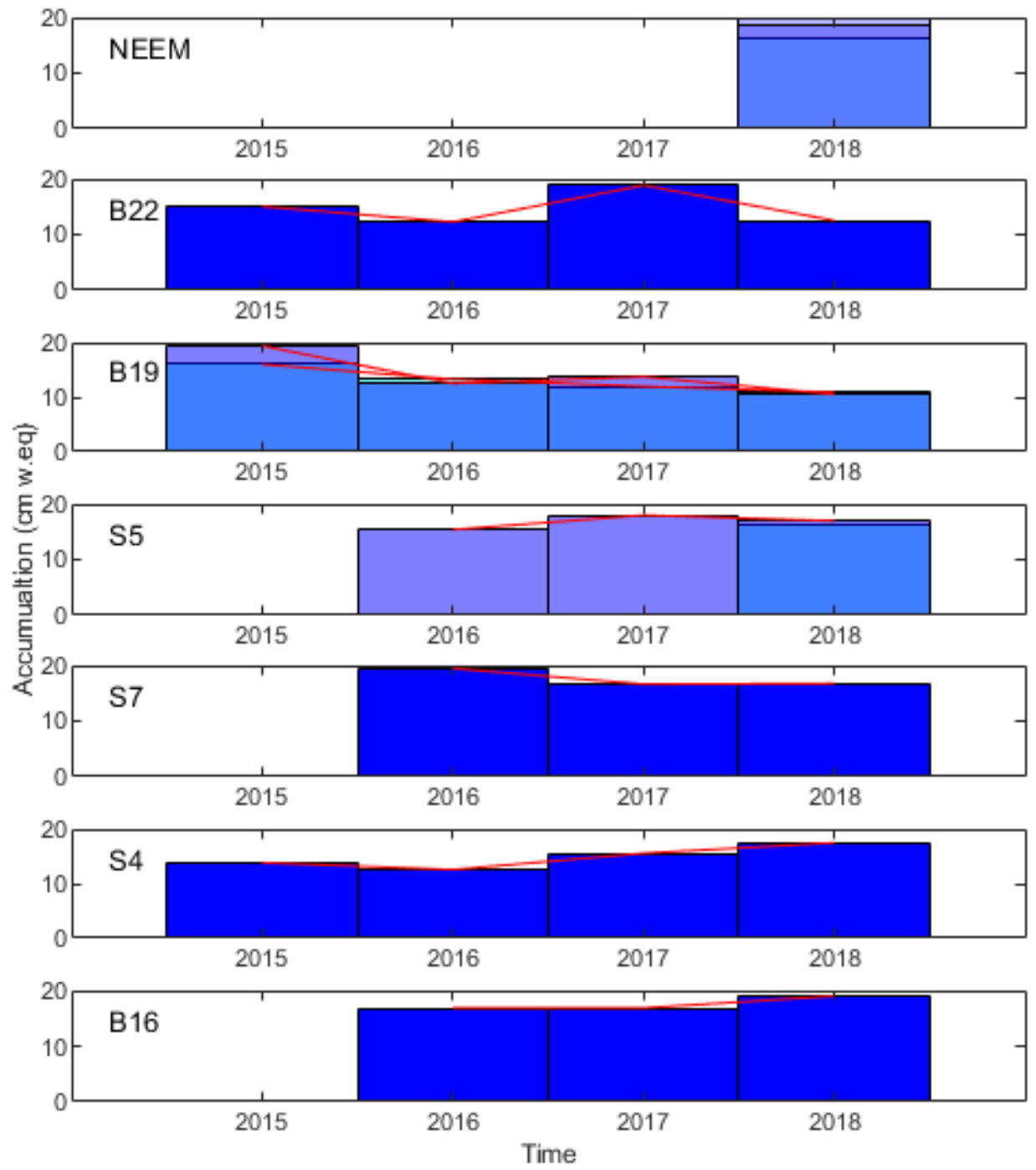

Figure S4: Accumulation (cm water equivalent per year) with time as observed in the snow cores analyzed by means of LISA. Note that they are derived from summer to summer. 